\title{
Field Verification of Superpave Dynamic Modulus
}

\author{
Daba S. Gedafa, Ph.D., EIT, Aff.ASCE${ }^{1}$; Mustaque Hossain, Ph.D., P.E., F.ASCE²; \\ Stefan Romanoschi, Ph.D., P.E., M.ASCE ${ }^{3}$; and Andrew J. Gisi, P.E., M.ASCE
}

\begin{abstract}
In the mechanistic-empirical pavement design guide, prediction of flexible pavement response and performance needs an input of dynamic modulus of hot-mix asphalt at all three levels of hierarchical inputs. This study was intended to find the best way to predict/derive this input. Nine Superpave pavement sections were selected as test sections in this study. Deflection data on all test sections was collected with a Dynatest 8000 falling weight deflectometer shortly after construction. The deflection data, normalized with respect to $40-\mathrm{kN}$ load, were used to back-calculate asphalt layer moduli using three back-calculation algorithms. Laboratory dynamic modulus tests were conducted on asphalt concrete $(\mathrm{AC})$ cores and laboratory-compacted samples. Dynamic modulus was also estimated with the Witczak model, new Witczak model, and Hirsch model. The results show that the AC moduli obtained from various back-calculation programs used in the study are generally comparable. Laboratory dynamic modulus is comparable at $4{ }^{\circ} \mathrm{C}$, but the variation increases as the test temperature increases. The Witczak model underestimates the dynamic modulus at low temperature and overestimates it at higher temperature. The parameter estimate when the laboratory dynamic modulus is used as a dependent variable and the moduli from other approaches as independent variables is close to 1 . This is especially true for the AC moduli estimated by various prediction methods. The Hirsch model appears to be the best for estimation and is closely followed by the new Witczak model.
\end{abstract}

DOI: 10.1061/(ASCE)MT.1943-5533.0000048

CE Database subject headings: Flexible pavements; Asphalts; Mixtures; Models.

Author keywords: Superpave mixtures; Dynamic modulus; MEPDG.

\section{Introduction}

The design methods adopted in the NCHRP 1-37A guide for mechanistic-empirical design of new and rehabilitated pavement Structures (National Cooperative Highway Research Program 2004) are based on mechanistic-empirical principles. This guide is popularly known as mechanistic-empirical pavement design guide (MEPDG). In this guide, prediction of pavement response and performance must take into account fundamental properties of layer materials. Among these, the most important property of hot-mix asphalt (HMA), a relatively new concept to the state highway agencies, is the dynamic modulus of asphalt concrete. This property represents the temperature- and frequencydependent (and therefore, time-dependent) stiffness characteristics of the HMA material. Extensive research effort has resulted in a standard test protocol that can be used for the simple perfor-

\footnotetext{
${ }^{1}$ Research Associate, Dept. of Civil Engineering, 2118 Fiedler Hall, Kansas State Univ., Manhattan, KS 66506 (corresponding author). E-mail: daba@ksu.edu

${ }^{2}$ Professor, Dept. of Civil Engineering, 2118 Fiedler Hall, Kansas State Univ., Manhattan, KS 66506. E-mail: mustak@ksu.edu

${ }^{3}$ Associate Professor, Department of Civil Engineering, 408 Nedderman Hall, The University of Texas at Arlington, Arlington, TX 76019. E-mail: romanoschi@uta.edu

${ }^{4}$ Geotechnical Engineer, Kansas Dept. of Transportation, Materials and Research Center, 2300 Van Buren, Topeka, KS 66611. E-mail: agisi@ksdot.org

Note. This manuscript was submitted on January 2, 2009; approved on September 5, 2009; published online on October 2, 2009. Discussion period open until October 1, 2010; separate discussions must be submitted for individual papers. This paper is part of the Journal of Materials in Civil Engineering, Vol. 22, No. 5, May 1, 2010. CASCE, ISSN 0899-1561/2010/5-485-494/\$25.00.
}

mance test for superpave mix design (NCHRP 2002). The protocol calls for use of axial compression testing for measuring dynamic modulus. One of the issues related to the dynamic modulus is its use in forensic studies and pavement rehabilitation design.

In the hierarchical design approach proposed in MEPDG for new HMA pavements, direct measurements of dynamic modulus are required for the highest design reliability (Level 1), which is intended for pavements with very high traffic volumes. However, dynamic modulus is used as the primary stiffness property for HMA at all three levels of hierarchical inputs in MEPDG.

In the overlay analysis of existing HMA pavements, the modulus of the existing HMA pavements is characterized by a damaged modulus that represents the condition at the time of overlay placement. However, according to MEPDG, the laboratory dynamic modulus tests are not needed for measuring the in-place modulus because the test must be performed on intact, but age-hardened specimens. In fact, MEPDG contends that the resulting modulus values will likely be higher than those for new HMA mixtures. Thus, MEPDG recommends that the modulus be determined from the deflection basin tests. However, no correlation between the laboratory dynamic modulus of asphalt concrete (AC) mixture and the back-calculated AC layer modulus has been established to date.

The dynamic modulus test is relatively difficult and expensive to perform. Therefore, numerous attempts have been made to develop regression equations to estimate the dynamic modulus from mixture volumetric properties. The predictive model developed by Witczak et al. (2002) is one of the most comprehensive mixture dynamic modulus models available to date that can predict the dynamic modulus of dense-graded HMA mixtures. A revised version of this model has been recommended in the design of 
Table 1. Layer Type and Thickness

\begin{tabular}{|c|c|c|c|c|c|c|c|}
\hline Layer number & Layer type & Material type & & & $\begin{array}{l}\text { Thickness } \\
\text { (mm) }\end{array}$ & & \\
\hline \multicolumn{8}{|l|}{ a. New projects } \\
\hline & & & U.S.-54 & U.S.-77 & U.S.-283 & $\mathrm{K}-7$ & K-99 \\
\hline & & & Butler & Butler & Graham & Doniphan & Elk \\
\hline 1 & Surface & SM-9.5A (PG 64-28) & $40^{\mathrm{a}}$ & 40 & 40 & 40 & 40 \\
\hline 2 & Binder & SM-19A (PG 64-28) & 60 & 60 & 60 & 60 & 60 \\
\hline 3 & Base & SM-19A (PG 64-22) & 220 & 200 & 180 & 120 & 180 \\
\hline 4 & Aggregate Base & AB-3 & N.A. & N.A. & N.A. & 280 & N.A. \\
\hline 5 & Subgrade & Modified Subgrade & $150^{\mathrm{b}}$ & $150^{\mathrm{b}}$ & $150^{\mathrm{b}}$ & $150^{\mathrm{c}}$ & $150^{\mathrm{b}}$ \\
\hline \multicolumn{8}{|c|}{ b. U.S.-75 test sections } \\
\hline & & & S-1 & $S-2$ & S-3 & S-4 & \\
\hline 1 & Surface & SM-9.5A (PG 70-28) & 40 & 40 & 40 & 40 & \\
\hline 2 & Binder & SM-19A (PG 70-28) & 60 & 60 & 60 & 60 & \\
\hline \multirow[t]{2}{*}{3} & Base & SM-19A (PG 64-22) & N.A. & 187.5 & 225 & 300 & \\
\hline & & SM-19A (PG70-22) & 225 & N.A. & N.A. & N.A. & \\
\hline 4 & Subgrade & Lime Treated Subgrade & $150^{\mathrm{b}}$ & $150^{\mathrm{b}}$ & $150^{\mathrm{b}}$ & $150^{\mathrm{b}}$ & \\
\hline
\end{tabular}

Note: N.A. means not applicable.

${ }^{\mathrm{a}} \mathrm{SM}-9.5 \mathrm{~T}$ PG 64-28.

${ }^{\mathrm{b}}$ Lime treated subgrade.

${ }^{c}$ Fly ash modified subgrade.

intermediate- and low-volume roadways (design Levels 2 and 3) in MEPDG (AASHTO 2008).

\section{Problem Statement}

Adoption of MEPDG for new asphalt pavement design would require the dynamic modulus of HMA mixture as the basic input parameter. The dynamic modulus is measured in the laboratory during design phase using samples compacted by the superpave gyratory compactor (SGC). However, verification is needed whether this input parameter can be achieved in the asconstructed pavement. This can be done through in situ deflection tests using a falling weight deflectometer (FWD) and corresponding laboratory tests on the cores taken from the constructed pavements.

\section{Objectives of the Study}

The objectives of this study were as follows:

- Compare laboratory dynamic modulus with estimated dynamic modulus from various prediction models as well as those backcalculated from FWD data; and

- Develop a correction procedure for the input modulus of Superpave mixtures based on back-calculated, laboratoryderived, and estimated dynamic moduli.

\section{Test Sections}

Five newly built Superpave pavements, designed using 1993 AASHTO Design Guide, and four Superpave pavement test sections on the Kansas perpetual pavement project on U.S.-75 were selected as experimental sections in this study. Table 1 indicates the layer type and thicknesses of these sections.
All new pavement sections have a surface course of $40 \mathrm{~mm}$ thickness. The layer consists of 9.5-mm nominal maximum aggregate size Superpave mixture (known as SM-9.5A and SM-9.5T in Kansas) with PG 64-28 binder. Layers 2 and 3 are composed of fine graded 19-mm nominal maximum aggregate size Superpave mixture (SM-19A) with PG 64-28 and PG 64-22 binders, respectively. The base layer thickness varies from 120 to $220 \mathrm{~mm}$. The K-7 project in Doniphan County has the thinnest asphalt base layer $(120 \mathrm{~mm})$ since it also has $280 \mathrm{~mm}$ crushed aggregate base designated as AB-3 in Kansas.

On the perpetual pavement project on U.S.-75, Section 1 (S-1), Section 2 (S-2), and Section 3 (S-3) were designed by the Kansas Asphalt Pavement Association (KAPA) whereas Section 4 (S-4), thickest section, was designed by the Kansas Department of Transportation (KDOT). Sections 1 and 3 have the same thickness, but Section 3 has a softer binder in the base layer. Section 2 has a predicted fatigue life of 30 million ESALs/lane, which corresponds to a reliability factor of about 5.2 (a reliability level of $85 \%$ ). Thus it was named the high reliability section (Romanoschi et al. 2008). All projects have lime-treated subgrade except K-7 in Doniphan County where subgrade was modified with a Class $\mathrm{C}$ fly ash.

\section{Data Collection}

\section{Deflection Data}

Deflection data was collected with a Dynatest 8000 FWD approximately $8-10$ weeks after construction. Multiple target loads were used on most projects to evaluate the stress sensitivity of the materials in the pavement structure. The load pulse duration was in between 25 and $30 \mathrm{~ms}$. This frequency enabled us to compare back-calculated HMA moduli with the laboratory-measured and estimated dynamic moduli at $25 \mathrm{~Hz}$.

The target loads used in FWD testing were 40, 53, and/or 67 
Table 2. Summary of Volumetric Properties for New Projects

\begin{tabular}{|c|c|c|c|c|c|c|c|c|c|c|c|c|c|c|c|}
\hline & \multicolumn{3}{|c|}{ U.S.-54 } & \multicolumn{3}{|c|}{ U.S.-77 } & \multicolumn{3}{|c|}{ U.S.-283 } & \multicolumn{3}{|c|}{ K-7 } & \multicolumn{3}{|c|}{ K-99 } \\
\hline & Surface & Binder & Base & Surface & Binder & Base & Surface & Binder & Base & Surface & Binder & Base & Surface & Binder & Base \\
\hline$\rho_{200}$ & 4.7 & 4.3 & 3.5 & 4.0 & 5.3 & 2.6 & 4.0 & 4.9 & 4.7 & 3.3 & 4.6 & 2.9 & 2.2 & 2.8 & 2.9 \\
\hline$\rho_{4}$ & 27.0 & 37.0 & 33.0 & 23.0 & 36.0 & 37.0 & 26.0 & 32.0 & 28.0 & 22.0 & 44.0 & 37.0 & 28.0 & 41.0 & 34.0 \\
\hline$\rho_{3 / 8}$ & 2.0 & 18.0 & 17.0 & 3.0 & 17.0 & 17.0 & 6.0 & 18.0 & 19.0 & 2.0 & 29.0 & 20.0 & 5.0 & 24.0 & 18.0 \\
\hline$\rho_{3 / 4}$ & 0.0 & 3.0 & 3.0 & 0.0 & 3.0 & 2.0 & 0.0 & 2.0 & 2.0 & 0.0 & 0.0 & 0.0 & 0.0 & 4.0 & 1.0 \\
\hline Gse & 2.6 & 2.6 & 2.6 & 2.6 & 2.6 & 2.6 & 2.6 & 2.6 & 2.6 & 2.6 & 2.6 & 2.6 & 2.6 & 2.6 & 2.6 \\
\hline Gsb & 2.5 & 2.5 & 2.6 & 2.5 & 2.5 & 2.5 & 2.6 & 2.6 & 2.6 & 2.5 & 2.5 & 2.5 & 2.5 & 2.5 & 2.5 \\
\hline Gmb & 2.3 & 2.3 & 2.3 & 2.3 & 2.3 & 2.3 & 2.3 & 2.3 & 2.3 & 2.2 & 2.2 & 2.2 & 2.3 & 2.3 & 2.3 \\
\hline $\mathrm{Gmm}$ & 2.4 & 2.4 & 2.4 & 2.4 & 2.4 & 2.4 & 2.4 & 2.4 & 2.4 & 2.4 & 2.4 & 2.4 & 2.4 & 2.4 & 2.4 \\
\hline $\mathrm{Gb}$ & 1.0 & 1.0 & 1.0 & 1.0 & 1.0 & 1.0 & 1.0 & 1.0 & 1.0 & 1.0 & 1.0 & 1.0 & 1.0 & 1.0 & 1.0 \\
\hline$\% \mathrm{AC}$ & 6.0 & 5.6 & 5.2 & 6.1 & 5.5 & 5.2 & 5.8 & 4.9 & 4.8 & 6.4 & 5.7 & 5.7 & 6.8 & 5.5 & 5.5 \\
\hline VMA & 16.9 & 16.2 & 16.5 & 15.6 & 14.8 & 14.1 & 16.2 & 15.6 & 15.2 & 17.6 & 15.9 & 16.3 & 17.3 & 15.7 & 16.1 \\
\hline VFA & 72.6 & 64.3 & 60.7 & 74.4 & 69.2 & 65.5 & 72.2 & 62.4 & 64.1 & 64.2 & 59.9 & 58.1 & 74.3 & 61.3 & 58.1 \\
\hline$V \mathrm{a}$ & 4.6 & 5.8 & 6.5 & 4.0 & 4.6 & 4.9 & 4.5 & 5.9 & 5.5 & 6.3 & 6.4 & 6.8 & 4.5 & 6.1 & 6.8 \\
\hline Veff & 12.7 & 10.9 & 10.2 & 12.0 & 10.5 & 9.6 & 12.1 & 9.7 & 10.0 & 11.7 & 9.9 & 9.8 & 13.4 & 10.0 & 9.8 \\
\hline
\end{tabular}

Note: $\rho_{200}=$ percent passing sieve $0.075 \mathrm{~mm} ; \rho_{4}, \rho_{3 / 8}, \rho_{3 / 4}=$ cumulative percent retained on 4.75-, 9.5-, and 19-mm sieves, respectively; Gse, Gsb $=$ effective and bulk specific gravities of aggregate, respectively; Gmb and Gmm=bulk and theoretical maximum specific gravity of the mixture, respectively; \% AC and $\mathrm{Gb}=$ percent asphalt content and asphalt specific gravity, respectively; VMA and VFA=voids in the mineral aggregates $(\%)$ and percent of VMA filled with binder (\%), respectively; and $V$ a and $V$ eff=air voids (\%) and effective asphalt content (\%), respectively.

$\mathrm{kN}$ for all new projects and $40 \mathrm{kN}$ for all U.S.-75 test sections. Deflection measurements were made in the outside wheel path of the travel lane at 11 stations at $30 \mathrm{~m}$ intervals on all new projects. FWD data at seven to nine stations were collected on the U.S.-75 test sections. The geophone spacing was $0,200,300,450,600$, 900, and 1,200 $\mathrm{mm}$ for U.S.-54, U.S.-77, and U.S.-283. The last sensor was located at 1,500 $\mathrm{mm}$ for K-7 and K-99 projects and on all U.S.-75 test sections. The pavement surface temperature was measured at the time of testing. This temperature varied from 17 to $59^{\circ} \mathrm{C}$ for all new projects and 12 to $40^{\circ} \mathrm{C}$ for the U.S. -75 test sections. The variation in temperature for the U.S.-75 test sections was due to time difference, though testing was done on the same day.

\section{Samples for Laboratory Dynamic Modulus Test}

On all new projects, full depth, 100-mm-diameter cores were taken at the same locations where FWD deflections tests had been done. Later the samples were trimmed to the required height of $150 \mathrm{~mm}$ for dynamic modulus testing. Some thicker cores were cut into two 150-mm samples, whereas base layer (bottom) of thinner cores was cut to $150-\mathrm{mm}$ sample. No cores were taken from the test sections on U.S.-75. Dynamic modulus test samples for these test sections were prepared from the mixtures mixed in the laboratory and compacted by the SGC. The 150 -mm-diameter SGC-compacted samples were then cored in the laboratory to get 100-mm-diameter dynamic modulus test samples.

\section{Volumetric Properties for Estimating Dynamic Modulus}

Most data required for predicting dynamic modulus using the Witczak model, new Witczak model, and Hirsch model were obtained from the mixture design. Design information includes gradation of aggregates (cumulative percent retained on 4.75-, 9.5-, and $19-\mathrm{mm}$ sieves and percent passing sieve of $0.075 \mathrm{~mm}$ ), physical properties of the aggregates (bulk and effective specific gravities), asphalt content and asphalt specific gravity, and theoretical maximum specific gravity of the mixture. Bulk specific gravities of the compacted samples and the cores were determined in the laboratory based on the Kansas Standard Test Method KT-15, Procedure III. KT-15 closely follows AASHTO T 166 (AASHTO 2001a). From these pieces of information, the air void (\%), effective bitumen content ( $\%$ by volume), voids in the mineral aggregates $(\%)$, and percent of VMA filled with binder $(\%)$ were calculated. Table 2 shows summary of volumetric properties for the mixtures in the new projects.

\section{Data Analysis}

\section{Back-Calculation of Layer Moduli}

All deflections were normalized to 40-kN FWD load and were used to back-calculate the moduli of AC layers based on multilayered linear elastic theory. Pavement sections were modeled as three-layer systems by combining all AC layers into one. Comparison of solutions from different back-calculation algorithms gives an idea of the range of values that can be expected (Chou and Lytton 1991). Thus, three back-calculation computer programs, EVERCALC, MODCOMP 5, and MODULUS, were used in this study.

In the back-calculation of pavement layer moduli, the objective is to identify a set of pavement layer moduli that would produce a deflection basin matching the measured deflection basin. Since only a finite number of sensor data points are available from the deflection measurements, the objective function in back-calculation analysis typically involves minimization of the root-mean-square difference $\left(D_{\text {rms }}\right)$ of the measured and computed deflections. A solution that has a smaller $D_{\text {rms }}$, derived from Eq. (1), is considered to be a better fit, and thus a better solution (Fwa et al. 1997)

$$
\text { minimize } D_{\mathrm{rms}}=\sqrt{\frac{1}{m} \sum_{i=1}^{m}\left(\frac{d_{i}-D_{i}}{D_{i}}\right)}
$$

where $m=$ number of deflection-measurement points; $d_{i}=$ back-calculated deflection at point $i$; and $D_{i}=$ measured deflection at point $i$. 


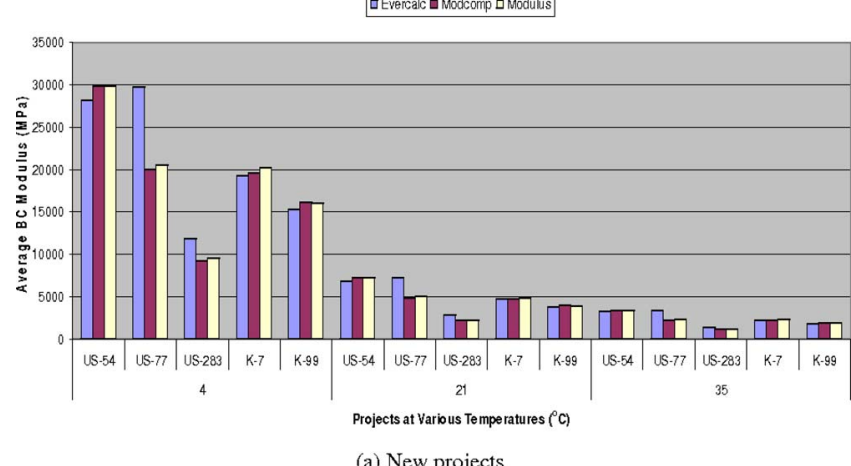

(a) New projects

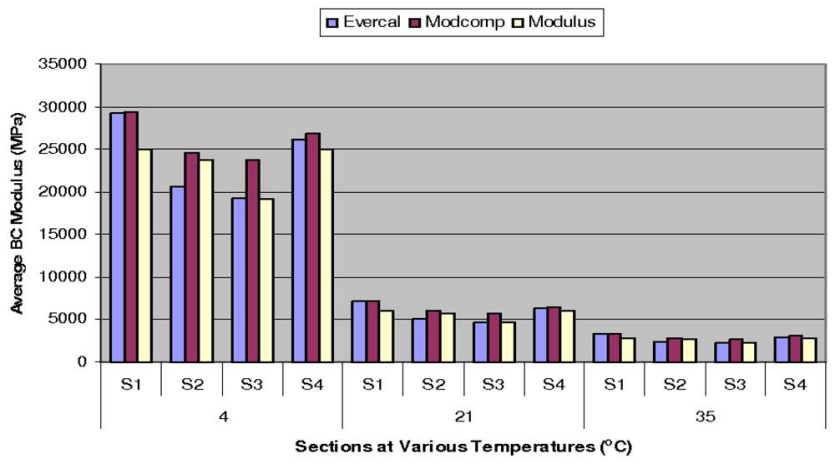

(b) US-75 test sections

Fig. 1. Comparison of average back-calculated moduli at various temperatures: (a) new projects; (b) U.S.-75 test sections

\section{Temperature Correction of Back-Calculated AC Modulus}

The most important environmental factor affecting surface deflections and back-calculated AC moduli of flexible pavements is the temperature of the AC layer (Kim and Lee 1995; Park and Kim 1997; Shao et al. 1997; Park et al. 2002). Since FWD testing is performed at different temperatures, the back-calculated AC moduli need to be adjusted to a standard temperature to allow for a direct comparison between the back-calculated moduli and other moduli.

To determine corrected AC modulus, a two-step correction procedure is needed. Typically, the first step consists of predicting the effective temperature of the AC layer and the second step consists of adjusting the computed modulus to a reference temperature using a correction factor (Park et al. 2001). This two-step procedure was followed in this study.

AC layer temperature: using measured pavement temperatures at different depths from the long-term pavement performance database, Inge and Kim (1995) developed the BELLS equation for predicting AC layer temperature at the one-third depth. A third model, BELLS3, was subsequently developed for use during routine FWD testing when pavement surface is typically shaded for less than a minute. BELLS3 model [Eq. (2)] was used in this study to calculate mid-depth pavement temperature (Federal Highway Administration 2000).

$$
\begin{aligned}
T_{d}= & 0.95+0.892 T_{s}+(\log d-1.25) \times\left[1.83 \sin \left(2 \pi \frac{A}{18}\right)\right. \\
& \left.-0.448 T_{s}+0.621 T_{\text {avg }}\right]+0.042 T_{s} \sin \left(2 \pi \frac{B}{18}\right)
\end{aligned}
$$

where $T_{d}$ =pavement temperature at layer mid-depth $\left({ }^{\circ} \mathrm{C}\right) ; T_{s}$
$=$ infrared surface temperature $\left({ }^{\circ} \mathrm{C}\right) ; T_{\text {avg }}=$ average of high and low air temperatures on the day before testing $\left({ }^{\circ} \mathrm{C}\right)$; and $d$ $=$ layer mid-depth (mm). $A$ and $B$ are computed as follows:

$$
\begin{aligned}
& A=\left\{\begin{array}{ll}
t_{d}+9.5 & \text { if } 0 \leq t_{d}<5 \\
-4.5 & \text { if } 5 \leq t_{d}<11 \\
t_{d}-15.5 & \text { if } 11 \leq t_{d}<24
\end{array}\right. \text { and } \\
& B= \begin{cases}t_{d}+9.5 & \text { if } 0 \leq t_{d}<3 \\
-4.5 & \text { if } 3 \leq t_{d}<9 \\
t_{d}-13.5 & \text { if } 9 \leq t_{d}<24\end{cases}
\end{aligned}
$$

where $t_{d}=$ time of day (in decimal hours).

The last two variables are used as arguments to a pair of sine functions with $18 \mathrm{~h}$ periods, and 15.5- and 13.5-h phase lags, respectively. One cycle per day is allowed. During the other six hours of the day, $A$ and $B$ are set equal to -4.5 so that the sine functions return a value of -1 .

Temperature correction for AC modulus: Chen et al. (2000) developed Eq. (3) based on deflection data from intact locations. This equation was used in this study since it can be used to adjust AC modulus to any temperature. AC modulus was corrected to 4 , 21 , and $35^{\circ} \mathrm{C}$ temperature to compare with the laboratory and estimated moduli.

$$
E_{T_{w}}=\frac{E_{T_{c}}}{\left[\left(1.8 T_{w}+32\right)^{2.4462} \times\left(1.8 T_{c}+32\right)^{-2.4462}\right]}
$$

where $E_{T_{w}}=$ adjusted modulus of elasticity at $T_{w}(\mathrm{MPa}) ; E_{T_{c}}$ $=$ measured modulus of elasticity at $T_{c}(\mathrm{MPa}) ; T_{w}=$ temperature to which the modulus of elasticity is adjusted $\left({ }^{\circ} \mathrm{C}\right)$; and $T_{c}=$ mid-depth temperature at the time of FWD data collection $\left({ }^{\circ} \mathrm{C}\right)$.

\section{Laboratory Tests for Dynamic Modulus}

Dynamic modulus tests were conducted using a universal testing machine (UTM-25). AASHTO TP: 62-03 (standard method of test for determining dynamic modulus of HMA concrete mixtures) (AASHTO 2001b) was followed except for some minor modifications in test temperature and frequencies. Modifications were made in order to match the temperatures and frequencies of back-calculated and estimated moduli from prediction models. Tests at low temperature also takes time and cause freezing of the UTM, whereas at high temperature, samples start softening and LVDTs could not be glued to the samples. In this study, three temperatures: 4,21 , and $35^{\circ} \mathrm{C}$, and six frequencies: $0.1,0.5,1,5$, 10 , and $25 \mathrm{~Hz}$, were used.

\section{Computation of Dynamic Modulus Using Prediction Models}

The effect of aging was incorporated in dynamic modulus estimation using the global aging system (Mirza and Witczak 1995). The original, mix/lay-down, surface aging, and aging at different depths and corresponding viscosities were determined at different temperatures $\left(4,21\right.$, and $\left.35^{\circ} \mathrm{C}\right)$ and frequencies $(0.1,0.5,1,5,10$, and $25 \mathrm{~Hz}$ ). Temperature data for different project locations was obtained from the weather data library at Kansas State University. Dynamic modulus of the asphalt pavement layer material was estimated using the Witczak model, new Witczak model, and Hirsch model.

Witczak model: the predictive model developed by Witczak et al. (2002) is one of the most comprehensive mixture dynamic 
Table 3. Summary Statistics of Back-Calculated AC Modulus at Various Temperatures

\begin{tabular}{|c|c|c|c|c|c|c|c|c|c|c|}
\hline \multirow[b]{2}{*}{$\begin{array}{l}\text { Temp. } \\
\left({ }^{\circ} \mathrm{C}\right)\end{array}$} & & \multicolumn{3}{|c|}{ EVERCALC } & \multicolumn{3}{|c|}{ MODCOMP } & \multicolumn{3}{|c|}{ MODULUS } \\
\hline & & $\begin{array}{l}\text { Average mod. } \\
\quad(\mathrm{MPa})\end{array}$ & $\begin{array}{c}\mathrm{SD} \\
(\mathrm{MPa})\end{array}$ & $\begin{array}{c}\mathrm{COV} \\
(\%)\end{array}$ & $\begin{array}{l}\text { Average mod. } \\
(\mathrm{MPa})\end{array}$ & $\begin{array}{l}\mathrm{SD} \\
(\mathrm{MPa})\end{array}$ & $\begin{array}{c}\mathrm{COV} \\
(\%)\end{array}$ & $\begin{array}{l}\text { Average mod. } \\
(\mathrm{MPa})\end{array}$ & $\begin{array}{c}\mathrm{SD} \\
(\mathrm{MPa})\end{array}$ & $\begin{array}{l}\mathrm{COV} \\
(\%)\end{array}$ \\
\hline \multicolumn{11}{|c|}{ (a) New projects } \\
\hline \multirow[t]{5}{*}{4} & U.S.-54 & 28,142 & $2,238.2$ & 8.0 & 29,844 & 1,609 & 5.4 & 29,913 & $24,61.9$ & 8.2 \\
\hline & U.S.-77 & 29,705 & $8,309.4$ & 28.0 & 19,987 & 1,834 & 9.2 & 20,515 & $2,627.8$ & 12.8 \\
\hline & U.S.-283 & 11,887 & $2,159.1$ & 18.2 & 9,279 & 942.5 & 10.2 & 9,438 & 834.0 & 8.8 \\
\hline & K-7 & 19,244 & 972.2 & 5.1 & 19,633 & 1,271 & 6.5 & 20,233 & $2,000.2$ & 9.9 \\
\hline & K-99 & 15,279 & $1,838.2$ & 12.0 & 16,177 & 1,136 & 7.0 & 15,965 & $1,108.8$ & 6.9 \\
\hline \multirow[t]{5}{*}{21} & U.S.-54 & 6,861 & 545.7 & 8.0 & 7,276 & 392.4 & 5.4 & 7,293 & 600.2 & 8.2 \\
\hline & U.S.-77 & 7,243 & $2,026.0$ & 28.0 & 4,873 & 447.1 & 9.2 & 5,002 & 640.7 & 12.8 \\
\hline & U.S.-283 & 2,898 & 526.4 & 18.2 & 2,262 & 229.8 & 10.2 & 2,301 & 203.3 & 8.8 \\
\hline & $\mathrm{K}-7$ & 4,692 & 237.2 & 5.1 & 4,787 & 310.3 & 6.5 & 4,933 & 487.5 & 9.9 \\
\hline & K-99 & 3,725 & 448.2 & 12.0 & 3,944 & 277.1 & 7.0 & 3,893 & 270.3 & 6.9 \\
\hline \multirow[t]{5}{*}{35} & U.S.-54 & 3,228 & 256.8 & 8.0 & 3,423 & 184.6 & 5.4 & 3,431 & 282.4 & 8.2 \\
\hline & U.S.-77 & 3,407 & 953.2 & 28.0 & 2,293 & 210.4 & 9.2 & 2,353 & 301.4 & 12.8 \\
\hline & U.S.-283 & 1,364 & 247.7 & 18.2 & 1,064 & 108.1 & 10.2 & 1,083 & 95.6 & 8.8 \\
\hline & K-7 & 2,207 & 111.7 & 5.1 & 2,252 & 145.5 & 6.5 & 2,321 & 487.5 & 9.9 \\
\hline & K-99 & 1,753 & 210.9 & 12.0 & 1,831 & 127.2 & 6.9 & 1,856 & 130.3 & 7.0 \\
\hline \multicolumn{11}{|c|}{ (b) U.S.-75 test sections } \\
\hline \multirow[t]{4}{*}{4} & S-1 & 29,282 & 1,577 & 5.4 & 29,344 & 2,231 & 7.6 & 25,029 & 839.7 & 3.4 \\
\hline & S-2 & 20,671 & 3,746 & 18.1 & 24,602 & 1,005 & 4.1 & 23,758 & $1,164.3$ & 4.9 \\
\hline & S-3 & 19,273 & 2,145 & 11.1 & 23,713 & 860.3 & 3.6 & 19,111 & $1,322.3$ & 6.9 \\
\hline & S-4 & 26,164 & 2,127 & 8.1 & 26,806 & 2,135 & 8.0 & 25,030 & $1,515.3$ & 6.1 \\
\hline \multirow[t]{4}{*}{21} & S-1 & 7,139 & 384.4 & 5.4 & 7,155 & 543.9 & 7.6 & 6,103 & 204.7 & 3.4 \\
\hline & S-2 & 5,040 & 913.2 & 18.1 & 5,998 & 244.9 & 4.1 & 5,792 & 283.9 & 4.9 \\
\hline & S-3 & 4,699 & 523.0 & 11.1 & 5,782 & 209.8 & 3.6 & 4,660 & 322.4 & 6.9 \\
\hline & S-4 & 6,379 & 518.6 & 8.1 & 6,536 & 520.6 & 8.0 & 6,103 & 369.5 & 6.1 \\
\hline \multirow[t]{4}{*}{35} & S-1 & 3,359 & 180.8 & 5.4 & 3,366 & 255.9 & 7.6 & 2,871 & 96.3 & 3.4 \\
\hline & S-2 & 2,371 & 429.6 & 18.1 & 2,822 & 115.2 & 4.1 & 2,725 & 133.6 & 4.9 \\
\hline & S-3 & 2,211 & 246.1 & 11.1 & 2,720 & 98.7 & 3.6 & 2,192 & 151.7 & 6.9 \\
\hline & S-4 & 3,001 & 244.0 & 8.1 & 3,075 & 244.9 & 8.0 & 2,871 & 173.8 & 6.1 \\
\hline
\end{tabular}

modulus models available today. It is capable of estimating dynamic modulus of dense-graded HMA mixtures over a range of temperature, rates of loading, and aging conditions from information that is usually available from the conventional binder tests and the volumetric properties of the HMA mixture. The Witczak predictive model is based on bitumen viscosity, loading frequency, air void content, effective bitumen content, cumulative percent retained on 19-, 9.5-, and 4.75-mm sieves, and percent passing $0.075 \mathrm{~mm}$ sieve.

Hirsch model: Hirsch (1962) developed a variation of the law of mixtures for modeling the mechanical behavior of asphalt concrete. During 1999-2001, Pellinen (2001) conducted dynamic modulus testing of 18 HMA mixtures. Christensen et al. (2003) developed a new dynamic modulus prediction model based on the Hirsch model. The database generated by Pellinen (2001) was used. The model combines the series and parallel elements of phases. In applying the Hirsch model to the asphalt concrete, the relative portion of material in parallel arrangement, called contact volume, is not constant but varies with time and temperature. This model, based on shear modulus of the binder, voids in the mineral aggregates, and percent of VMA filled with binder and contact volume, has been used in this study. Dynamic shear modulus was estimated using Bari's model (Bari 2005).

New Witczak model: Bari (2005) developed a comprehensive new Witczak model which uses air void content, effective bitumen content, percent retained on 19-, 9.5-, and 4.75-mm sieves, and percent passing the $0.075 \mathrm{~mm}$ sieve, dynamic shear modulus, and phase angle of binder as inputs. Bari (2005) also developed prediction models for dynamic shear modulus and phase angle of the binders. Dynamic shear modulus is estimated based on dynamic shear loading frequency, viscosity of asphalt binder as a function of loading frequency, temperature, and phase angle.

\section{Results and Discussions}

\section{Comparison of Back-Calculated AC Modulus}

Fig. 1 shows the comparison of back-calculated AC moduli obtained from different back-calculation programs at various temperatures. The AC moduli from different programs are comparable for all new projects except U.S.-77, where the backcalculated AC modulus using EVERCALC is very high. U.S.-54, which was tested at the lowest temperature, has the highest AC modulus and U.S.-283, which was tested at the highest temperature, has the lowest AC modulus. U.S.-77 and K-7 were tested at comparable temperature and their AC moduli are also comparable. This implies that the test temperature affects the backcalculated AC modulus significantly. 


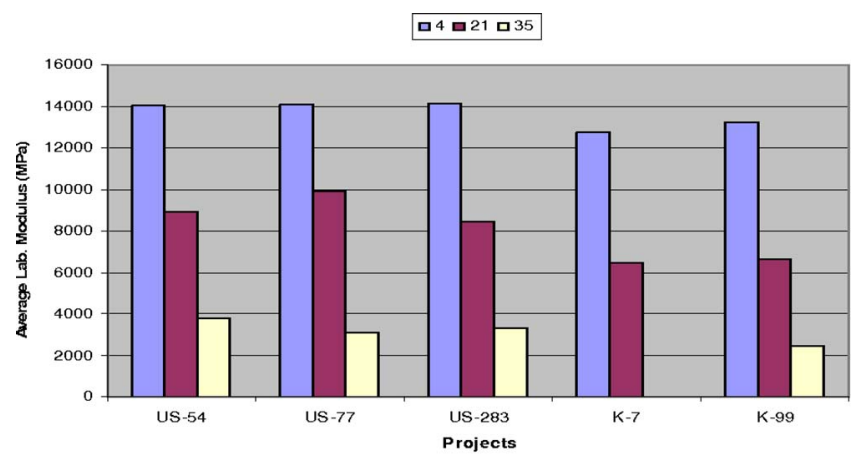

(a) New projects

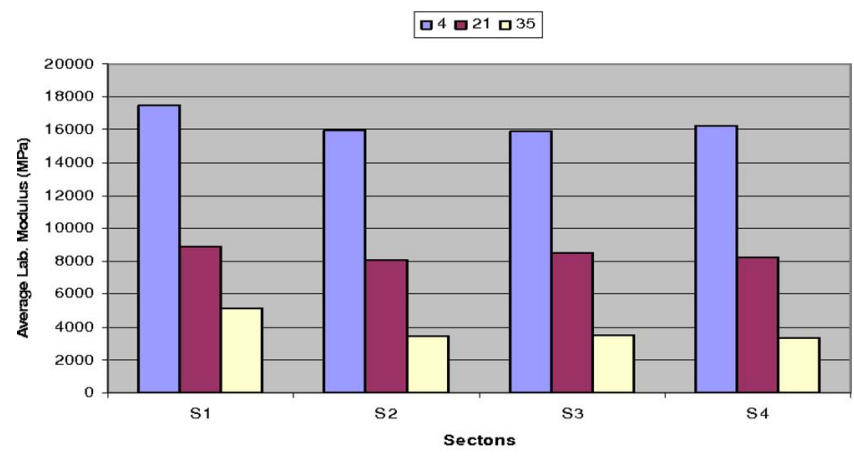

(b) US-75 test sections

Fig. 2. Laboratory dynamic modulus at various temperatures $\left({ }^{\circ} \mathrm{C}\right)$ : (a) new projects; (b) U.S.-75 test sections

The back-calculated AC moduli obtained from different backcalculation programs are also comparable for the U.S.-75 test sections. Sections 1-4 have modulus in a descending order. Section 1 was tested at a cooler temperature. Sections 2 and 4 were tested at comparable temperature. Section 4 has a very high backcalculated AC modulus since it is a very thick section. Section 3 was tested at a temperature cooler than 2 and thicker than 2, but the back-calculated AC modulus of this section is the lowest.

Table 3 lists the average back-calculated modulus, standard deviation (SD), and coefficient of variation (COV) for all new projects and U.S.-75 test sections. The standard deviation varies with the temperature whereas the $\mathrm{COV}$ remains about the same at

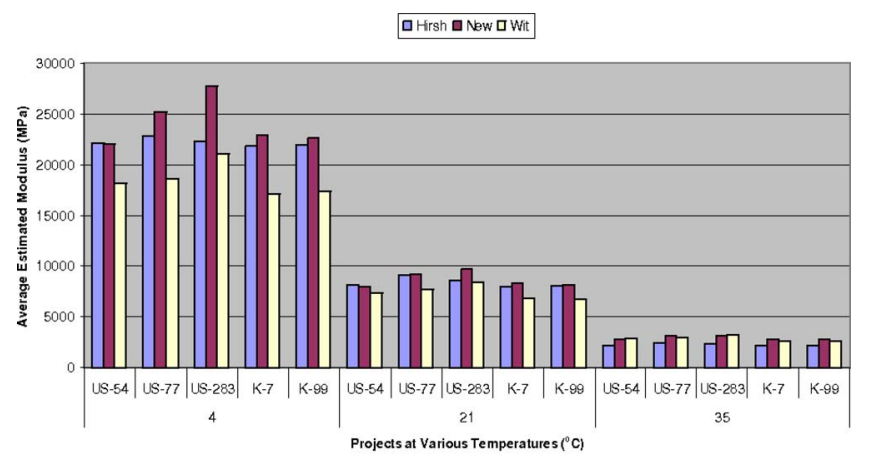

(a) New projects

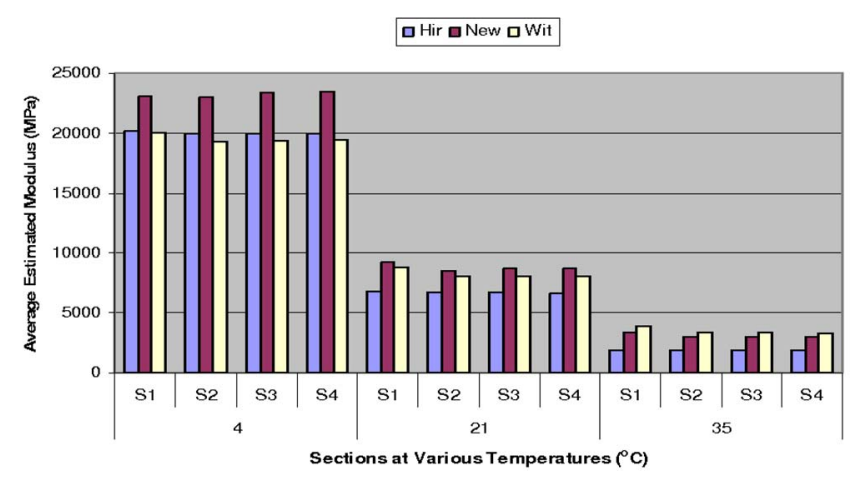

(b) US-75 test sections

Fig. 3. Dynamic modulus using prediction models at various temperatures: (a) new projects; (b) U.S.-75 test sections

all temperature levels. U.S.-77 has the highest average modulus, standard deviation, and COV for the EVERCALC results. U.S.-54 has the highest average AC modulus for MODCOMP and MODULUS. U.S.-77 has the highest standard deviation for the MODCOMP results and the highest standard deviation and COV for MODULUS results. K-7 has the lowest standard deviation and COV for the EVERCALC results. Overall there is no definite trend in the point statistics of the back-calculated moduli results. This is true for the new projects as well as for the U.S.-75 test sections.

Table 4. Comparison of Laboratory Dynamic Modulus at Various Temperatures

\begin{tabular}{|c|c|c|c|c|c|c|c|c|c|}
\hline & \multicolumn{3}{|c|}{$4^{\circ} \mathrm{C}$} & \multicolumn{3}{|c|}{$21^{\circ} \mathrm{C}$} & \multicolumn{3}{|c|}{$35^{\circ} \mathrm{C}$} \\
\hline & $\begin{array}{l}\text { Average mod. } \\
\quad(\mathrm{MPa})\end{array}$ & $\begin{array}{l}\mathrm{SD} \\
(\mathrm{MPa})\end{array}$ & $\begin{array}{l}\mathrm{COV} \\
(\%)\end{array}$ & $\begin{array}{l}\text { Average mod. } \\
\quad(\mathrm{MPa})\end{array}$ & $\begin{array}{c}\mathrm{SD} \\
(\mathrm{MPa})\end{array}$ & $\begin{array}{c}\mathrm{COV} \\
(\%)\end{array}$ & $\begin{array}{l}\text { Average mod. } \\
\text { (MPa) }\end{array}$ & $\begin{array}{c}\mathrm{SD} \\
(\mathrm{MPa})\end{array}$ & $\begin{array}{l}\mathrm{COV} \\
(\%)\end{array}$ \\
\hline \multicolumn{10}{|c|}{ (a) New projects } \\
\hline U.S.-54 & 14,045 & $2,098.1$ & 14.9 & $8,929.0$ & $1,172.2$ & 13.1 & 3,772 & 49.0 & 1.3 \\
\hline U.S.-77 & 14,059 & 777.1 & 5.5 & $9,894.3$ & $1,794.8$ & 18.1 & 3,110 & 136.5 & 4.4 \\
\hline U.S.-283 & 14,107 & $1,003.2$ & 7.1 & $8,453.3$ & $1,069.4$ & 12.7 & 3,296 & 59.3 & 1.8 \\
\hline $\mathrm{K}-7$ & 12,721 & $2,331.9$ & 18.3 & $6,446.8$ & $1,228.0$ & 19.1 & - & - & - \\
\hline K-99 & 13,202 & 309.5 & 2.3 & $6,622.4$ & 698.9 & 10.6 & 2,473 & 210.3 & 8.5 \\
\hline \multicolumn{10}{|c|}{ (b) U.S.-75 test sections } \\
\hline S-1 & 17,487 & & & $8,924.3$ & & & 5,108 & & \\
\hline$S-2$ & 15,939 & & & $8,068.5$ & & & 3,432 & & \\
\hline$S-3$ & 15,909 & & & $8,502.7$ & & & 3,493 & & \\
\hline S-4 & 16,250 & & & $8,212.8$ & & & 3,373 & & \\
\hline
\end{tabular}


Table 5. Dynamic Modulus Using Predictive Models at Various Temperatures

\begin{tabular}{|c|c|c|c|c|c|c|c|c|c|c|}
\hline \multirow[b]{2}{*}{$\begin{array}{l}\text { Temp } \\
\left({ }^{\circ} \mathrm{C}\right)\end{array}$} & & \multicolumn{3}{|c|}{ Hirsch model } & \multicolumn{3}{|c|}{ New Witczak model } & \multicolumn{3}{|c|}{ Witczak model } \\
\hline & & $\begin{array}{l}\text { Average mod. } \\
\quad(\mathrm{MPa})\end{array}$ & $\begin{array}{c}\mathrm{SD} \\
(\mathrm{MPa})\end{array}$ & $\begin{array}{c}\mathrm{COV} \\
(\%)\end{array}$ & $\begin{array}{l}\text { Average mod. } \\
\quad(\mathrm{MPa})\end{array}$ & $\begin{array}{c}\mathrm{SD} \\
(\mathrm{MPa})\end{array}$ & $\begin{array}{c}\mathrm{COV} \\
(\%)\end{array}$ & $\begin{array}{c}\text { Average } \\
\text { mod. } \\
(\mathrm{MPa})\end{array}$ & $\begin{array}{l}\mathrm{SD} \\
(\mathrm{MPa})\end{array}$ & $\begin{array}{c}\mathrm{COV} \\
(\%)\end{array}$ \\
\hline \multicolumn{11}{|c|}{ (a) New projects } \\
\hline \multirow[t]{5}{*}{4} & U.S.-54 & 22,070 & 156.2 & 0.7 & 21,996 & 397.6 & 1.8 & 18,080 & 365.3 & 2.0 \\
\hline & U.S.-77 & 22,862 & 294.2 & 1.3 & 25,154 & 808.3 & 3.2 & 18,647 & 512.0 & 2.7 \\
\hline & U.S.-283 & 22,349 & 267.2 & 1.2 & 27,781 & 840.3 & 3.0 & 21,102 & 601.5 & 2.9 \\
\hline & $\mathrm{K}-7$ & 21,807 & 154.0 & 0.7 & 22,926 & 410.4 & 1.8 & 17,107 & 347.8 & 2.0 \\
\hline & K-99 & 21,953 & 249.6 & 1.1 & 22,585 & 651.0 & 2.9 & 17,421 & 549.7 & 3.2 \\
\hline \multirow[t]{5}{*}{21} & U.S.-54 & 8,237 & 157.2 & 1.9 & 8,024 & 152.9 & 1.9 & 7,376 & 148.9 & 2.0 \\
\hline & U.S.-77 & 9,073 & 342.4 & 3.8 & 9,218 & 296.0 & 3.2 & 7,662 & 210.4 & 2.7 \\
\hline & U.S.-283 & 8,564 & 290.0 & 3.4 & 9,686 & 298.6 & 3.1 & 8,389 & 238.8 & 2.8 \\
\hline & $\mathrm{K}-7$ & 7,977 & 150.9 & 1.9 & 8,270 & 156.3 & 1.9 & 6,817 & 138.7 & 2.0 \\
\hline & K-99 & 8,107 & 250.0 & 3.1 & 8,180 & 247.1 & 3.0 & 6,752 & 213.3 & 3.2 \\
\hline \multirow[t]{5}{*}{35} & U.S.-54 & 2,197 & 53.7 & 2.4 & 2,749 & 54.5 & 2.0 & 2,858 & 57.9 & 2.0 \\
\hline & U.S.-77 & 2,496 & 125.4 & 5.0 & 3,166 & 101.0 & 3.2 & 2,957 & 81.2 & 2.7 \\
\hline & U.S.-283 & 2,324 & 103.4 & 4.5 & 3,181 & 99.2 & 3.1 & 3,278 & 93.4 & 2.8 \\
\hline & $\mathrm{K}-7$ & 2,119 & 51.1 & 2.4 & 2,809 & 55.5 & 2.0 & 2,673 & 54.4 & 2.0 \\
\hline & K-99 & 2,163 & 85.5 & 4.0 & 2,801 & 87.8 & 3.1 & 2,700 & 85.3 & 3.2 \\
\hline \multicolumn{11}{|c|}{ (b) U.S.-75 test sections } \\
\hline \multirow[t]{4}{*}{4} & S-1 & 20,151 & & & 23,132 & & & 20,068 & & \\
\hline & S-2 & 19,972 & & & 22,948 & & & 19,262 & & \\
\hline & $S-3$ & 20,005 & & & 23,374 & & & 19,405 & & \\
\hline & S-4 & 19,941 & & & 23,513 & & & 19,478 & & \\
\hline \multirow[t]{4}{*}{21} & S-1 & 6,825 & & & 9,218 & & & 8,879 & & \\
\hline & $S-2$ & 6,687 & & & 8,569 & & & 8,024 & & \\
\hline & $\mathrm{S}-3$ & 6,712 & & & 8,716 & & & 8,056 & & \\
\hline & S-4 & 6,663 & & & 8,766 & & & 8,049 & & \\
\hline \multirow[t]{4}{*}{35} & $S-1$ & 1,918 & & & 3,436 & & & 3,931 & & \\
\hline & $\mathrm{S}-2$ & 1,872 & & & 3,007 & & & 3,378 & & \\
\hline & $S-3$ & 1,880 & & & 3,040 & & & 3,375 & & \\
\hline & S-4 & 1,864 & & & 3,039 & & & 3,349 & & \\
\hline
\end{tabular}

\section{Comparison of Laboratory Dynamic Modulus}

All new projects except K-7 and K-99 have comparable average dynamic modulus at $4^{\circ} \mathrm{C}$ as indicated in Fig. 2. Some variations are observed at 21 and $35^{\circ} \mathrm{C}$. K-7 cores were not tested at $35^{\circ} \mathrm{C}$ since the sample started softening at this temperature and consequently, LVDTs could not be attached (glued) to the specimens. This was not observed for samples from the other projects.

For the test sections on U.S.-75, samples of six different mixes from different layers were tested. The dynamic modulus was then calculated using Eq. (4) for all sections based on the respective thickness of each mix in each section. As a result, only one modulus was calculated for each section as shown in Fig. 2(b)

$$
E_{\text {eq }}=\frac{\sum E_{i} d_{i}}{\sum d_{i}}
$$

where $E_{\mathrm{eq}}=$ equivalent dynamic modulus $(\mathrm{MPa}) ; E_{i}=$ dynamic modulus of mix in layer $i(\mathrm{MPa})$; and $d_{i}=$ thickness of mix in layer $i(\mathrm{~mm})$.

Sections 2-4 have comparable modulus at all temperatures. Section 1 has the highest dynamic modulus at all temperatures. This section has modified binder in the base layer.

Table 4 tabulates the summary statistics of the dynamic modulus test results of cored samples for the new projects and SGC- compacted specimens for the U.S.-75 test sections. All core samples were tested at $21^{\circ} \mathrm{C}$, and three samples were tested at 4 and $35^{\circ} \mathrm{C}$ for all new projects except K-7. K-7 has the highest standard deviation and coefficient of variation. K-99 has the lowest standard deviation and coefficient of variation. U.S.-54 has the highest average modulus, lowest standard deviation, and $\mathrm{COV}$ at $35^{\circ} \mathrm{C}$. Obviously dynamic modulus changes as the temperature changes but the degree of change depends upon mixture characteristics.

Dynamic modulus for Sections 1-4 are 8,924, 3,069, 8,503, and $8,213 \mathrm{MPa}$ at $21^{\circ} \mathrm{C}$, respectively. The test was done only at $21^{\circ} \mathrm{C}$ and Eq. (3) was used to convert to other temperatures. As a result, the trend is the same at all temperatures except change in magnitude.

\section{Estimated Dynamic Modulus Using Predicton Models}

Dynamic modulus was also estimated for each mix in each layer using aged viscosities at various depths from the prediction models. The equivalent AC modulus was computed using Eq. (4) based on individual thickness of each mixture. Fig. 3 illustrates the estimated AC dynamic moduli. The new Witczak model gave the highest average dynamic modulus for all new projects and 
Table 6. Comparison of Various Methods of Dynamic Modulus Estimation for New Projects at $21^{\circ} \mathrm{C}$

\begin{tabular}{|c|c|c|c|c|c|c|c|c|c|c|c|}
\hline \multirow[b]{2}{*}{ Dependent variable } & \multirow{2}{*}{$\begin{array}{l}\text { Independent } \\
\text { variable }\end{array}$} & \multicolumn{2}{|c|}{ U.S.-54 } & \multicolumn{2}{|c|}{ U.S.-77 } & \multicolumn{2}{|c|}{ U.S.-283 } & \multicolumn{2}{|c|}{$\mathrm{K}-7$} & \multicolumn{2}{|c|}{ K-99 } \\
\hline & & $p$ value & Similar & $p$ value & Similar & $p$ value & Similar & $p$ value & Similar & $p$ value & Similar \\
\hline \multirow[t]{6}{*}{ Hirsch } & New & 0.4078 & Yes & 0.7515 & Yes & $<.0001$ & Yes & 0.2366 & Yes & 0.6378 & Yes \\
\hline & Wit & 0.0017 & No & 0.0015 & No & 0.4157 & Yes & $<.0001$ & No & $<0.0001$ & No \\
\hline & $\mathrm{Lab}$ & 0.0203 & No & 0.0784 & Yes & 0.6065 & Yes & $<.0001$ & No & $<0.0001$ & No \\
\hline & MODCOMP & 0.0002 & No & $<.0001$ & No & $<.0001$ & No & $<.0001$ & No & $<0.0001$ & No \\
\hline & MODULUS & 0.0001 & No & $<.0001$ & No & $<.0001$ & No & $<.0001$ & No & $<0.0001$ & No \\
\hline & EVERCALC & $<.0001$ & No & $<.0001$ & No & $<.0001$ & No & $<.0001$ & No & $<0.0001$ & No \\
\hline \multirow[t]{5}{*}{ New Witczak } & Wit & 0.0171 & No & 0.0005 & No & $<.0001$ & No & $<.0001$ & No & $<0.0001$ & No \\
\hline & $\mathrm{Lab}$ & 0.0021 & No & 0.1468 & Yes & $<.0001$ & No & $<.0001$ & No & $<0.0001$ & No \\
\hline & MODCOMP & 0.0029 & No & $<.0001$ & No & $<.0001$ & No & $<.0001$ & No & $<0.0001$ & No \\
\hline & MODULUS & 0.0019 & No & $<.0001$ & No & $<.0001$ & No & $<.0001$ & No & $<0.0001$ & No \\
\hline & EVERCALC & $<.0001$ & No & $<.0001$ & No & $<.0001$ & No & $<.0001$ & No & $<0.0001$ & No \\
\hline \multirow[t]{4}{*}{ Witczak } & Lab & $<.0001$ & No & $<.0001$ & No & 0.7640 & Yes & 0.1889 & Yes & 0.4239 & Yes \\
\hline & MODCOMP & 0.5118 & Yes & $<.0001$ & No & $<.0001$ & No & $<.0001$ & No & $<0.0001$ & No \\
\hline & MODULUS & 0.4253 & Yes & $<.0001$ & No & $<.0001$ & No & $<.0001$ & No & $<0.0001$ & No \\
\hline & EVERCALC & 0.0098 & No & 0.2101 & Yes & $<.0001$ & No & $<.0001$ & No & $<0.0001$ & No \\
\hline \multirow[t]{3}{*}{$\mathrm{Lab}$} & MODCOMP & $<.0001$ & No & $<.0001$ & No & $<.0001$ & No & $<.0001$ & No & $<0.0001$ & No \\
\hline & MODULUS & $<.0001$ & No & $<.0001$ & No & $<.0001$ & No & $<.0001$ & No & $<0.0001$ & No \\
\hline & EVERCALC & $<.0001$ & No & $<.0001$ & No & $<.0001$ & No & $<.0001$ & No & $<0.0001$ & No \\
\hline \multirow[t]{2}{*}{ MODCOMP } & MODULUS & 0.8868 & Yes & 0.7576 & Yes & 0.8552 & Yes & 0.5518 & Yes & 0.7586 & Yes \\
\hline & EVERCALC & 0.0486 & No & $<.0001$ & No & 0.0039 & No & 0.7006 & Yes & 0.1827 & Yes \\
\hline MODULUS & EVERCALC & 0.0663 & Yes & $<.0001$ & No & 0.0065 & No & 0.3286 & Yes & 0.3032 & Yes \\
\hline
\end{tabular}

U.S.-75 test sections except on U.S.-54 at $4{ }^{\circ} \mathrm{C}$. However, at that temperature, the AC dynamic modulus from the new Witczak model is comparable with that from the Hirch model. The Witczak model gave the lowest average modulus at $4^{\circ} \mathrm{C}$. The trend changes with temperature. At higher temperature, dynamic modulus from the Witczak model decreases significantly. The change in trend is very significant. Dynamic moduli using the Witczak model are lowest at $4{ }^{\circ} \mathrm{C}$ and highest at $35^{\circ} \mathrm{C}$ for all test sections. Table 5 shows the summary statistics of the estimated dynamic moduli that were calculated based on volumetric data for all new projects and U.S.-75 test sections. The new Witczak model, Hirsch model, and Witczak model show highest to lowest average modulus for all new projects at all temperatures except on U.S.54. Hirsch model gave the highest modulus for U.S.-54. The COV increases as the temperature increases for all new projects. The standard deviation of AC moduli values, estimated from the Witczak model, for all new projects decreases as the temperature increases but no specific trend is evident for the Hirsch model. The $\mathrm{COV}$ and standard deviation were not computed for the U.S.-75 test sections since only one sample was prepared in the laboratory per mix from which air voids was determined to estimate dynamic modulus. Results in Table 5 shows that the Witczak model underestimates the dynamic modulus at low temperature and overestimates at high temperature.

Table 7. Moduli Correction Factors for New Projects at $21^{\circ} \mathrm{C}$

\begin{tabular}{|c|c|c|c|c|c|c|c|}
\hline \multirow[b]{2}{*}{ Dependent variable } & \multirow[b]{2}{*}{ Independent variable } & \multicolumn{6}{|c|}{ Parameter estimate } \\
\hline & & U.S.-54 & U.S.-77 & U.S.-283 & $\mathrm{K}-7$ & K-99 & Overall \\
\hline \multirow[t]{6}{*}{$\mathrm{Lab}$} & Hirsch & 1.08 & 1.09 & 0.99 & 0.81 & 0.82 & 0.97 \\
\hline & New & 1.10 & 1.07 & 0.87 & 0.79 & 0.81 & 0.93 \\
\hline & Witczak & 1.20 & 1.29 & 1.01 & 0.95 & 0.98 & 1.09 \\
\hline & MODCOMP & 1.23 & 2.01 & 3.70 & 1.34 & 1.68 & 1.61 \\
\hline & MODULUS & 1.23 & 1.95 & 3.64 & 1.29 & 1.70 & 1.59 \\
\hline & EVERCALC & 1.32 & 1.29 & 2.82 & 1.37 & 1.76 & 1.45 \\
\hline \multirow[t]{3}{*}{ MODCOMP } & Hirsch & 0.87 & 0.53 & 0.26 & 0.60 & 0.49 & 0.53 \\
\hline & New & 0.89 & 0.52 & 0.23 & 0.58 & 0.48 & 0.51 \\
\hline & Witczak & 0.97 & 0.63 & 0.27 & 0.71 & 0.58 & 0.60 \\
\hline \multirow[t]{3}{*}{ MODULUS } & Hirsch & 0.88 & 0.54 & 0.27 & 0.62 & 0.48 & 0.54 \\
\hline & New & 0.90 & 0.53 & 0.24 & 0.60 & 0.48 & 0.51 \\
\hline & Witczak & 0.98 & 0.64 & 0.27 & 0.73 & 0.58 & 0.60 \\
\hline \multirow[t]{3}{*}{ EVERCALC } & Hirsch & 0.82 & 0.73 & 0.34 & 0.59 & 0.46 & 0.60 \\
\hline & New & 0.84 & 0.72 & 0.30 & 0.57 & 0.45 & 0.57 \\
\hline & Witczak & 0.92 & 0.87 & 0.35 & 0.69 & 0.55 & 0.67 \\
\hline
\end{tabular}




\section{Statistical Analysis}

Statistical analysis for comparing dynamic moduli obtained from various approaches was done by the statistical analysis system software and the significant difference method. All comparison was made at $5 \%$ level of significance. Dynamic moduli obtained at a temperature of $21^{\circ} \mathrm{C}$ and at a frequency of $25 \mathrm{~Hz}$ were used for comparison. It is to be noted that conservative comparison can be made between the back-calculated moduli (obtained from deflections measured by FWD at a frequency of between 33 and 40 $\mathrm{Hz}$ ) and laboratory measured, and estimated dynamic moduli at $25 \mathrm{~Hz}$. Statistical analysis was done at $25 \mathrm{~Hz}$ only since comparison between back-calculated and other moduli at other frequencies was not reasonable.

Significant difference test: significant differences among the average AC moduli from various approaches were only investigated for the new projects because of lack of replicate values for the test sections on U.S.-75 test sections. The $p$ value was used to test the significance of the difference among the average dynamic moduli at $21^{\circ} \mathrm{C}$.

The analysis results have been tabulated in Table 6 . The results are spotty at best i.e., some approaches tend to give similar moduli for a certain project but not for all projects. There are two very consistent trends. Laboratory-determined and the backcalculated moduli are significantly different. MODCOMP and MODULUS give statistically similar results for all projects.

Correction factors: correction factor (parameter estimate) has been developed with SAS. The correction factor may help in getting the right dynamic modulus input into MEPDG. In this part of analysis, laboratory dynamic modulus, estimated modulus, and back-calculated modulus were taken as dependent variables and the other as independent variable. Table 7 tabulates the numerical values of the correction factor.

When the laboratory dynamic modulus is used as the dependent variable, the correction factor varies from 1.08 to 1.32 for U.S.-54, 1.07 to 2.01 for U.S.-77, 0.87 to 3.70 for U.S.-283, 0.79 to 1.37 for $\mathrm{K}-, 7$ and 0.81 to 1.76 for K-99. On average, the correction factor varies from 0.93 to 1.61 . The largest discrepancy was observed for U.S.-283 for back-calculated moduli where FWD testing was done at a very high temperature. The correction factors for the laboratory modulus and the estimated modulus are consistently close to 1.00 for all projects, with the Hirsch model being the best and that is closely followed by the new Witczak model. This is also evident from the results obtained for the U.S.-75 test sections where laboratory dynamic modulus tests were conducted on reconstituted samples. The correction factors will be used to obtain laboratory dynamic modulus that is required as input in MEPDG based on estimated and/or backcalculated moduli. The overall correction factors may be used for other sites since the new projects were selected from different parts of the state.

\section{Conclusions}

Based on this study, the following conclusions can be made:

- The back-calculated moduli from various back-calculation programs used in the study were generally comparable;

- Laboratory dynamic modulus was comparable for all new projects and U.S.-75 test sections at $4{ }^{\circ} \mathrm{C}$. The variation increased as the test temperature increased;

- The new Witczak model gave the highest predicted dynamic modulus at $4{ }^{\circ} \mathrm{C}$;
- The Witczak model underestimated the dynamic modulus at low temperature and overestimated at high temperature when compared with the laboratory modulus;

- The laboratory and back-calculated moduli were statistically different. The back-calculated moduli from MODCOMP and MODULUS are statistically similar for all projects; and

- The parameter estimate when the laboratory dynamic modulus was used as a dependent variable was close to 1.0 especially for the moduli estimated by various prediction models. This may indicate that the prediction models can be used for estimating dynamic modulus of superpave mixtures. The Hirsch model appears to be the best for estimation and is closely followed by the new Witczak model.

\section{Acknowledgments}

The writers would like to thank KDOT for sponsoring this study. The writers gratefully acknowledge the help of Mr. Cristian Dumitru, formerly with Kansas State University, in dynamic modulus testing for most projects.

\section{References}

AASHTO. (2001a). "Standard method of test for bulk specific gravity of compacted hot mix asphalt using saturated surface-dry specimens." AASHTO Designation T 166-05, Washington, D.C.

AASHTO. (2001b). "Standard method of test for determining dynamic modulus of hot-mix asphalt concrete mixtures." AASHTO Designation TP 62-03, Washington, D.C.

AASHTO. (2008). "Mechanistic-empirical pavement design guide: A manual of practice." Publication No. MEPDG-1, AASHTO, Washington, D.C.

Bari, J. (2005). "Development of a new revised version of the Witczak $E^{*}$ predictive models for hot mix asphalt mixtures." Ph.D. dissertation, Arizona State Univ., Tempe.

Chen, D. H., Bilyeu, J., Lin, H. H., and Murphy, M. (2000). "Temperature correction on falling weight deflectometer measurements." Transportation Research Record. 1716, Transportation Research Board, Washington, D.C., 30-39.

Chou, Y. J., and Lytton, R. L. (1991). "Accuracy and consistency of back-calculated pavement layer moduli." Transportation Research Record. 1022, Transportation Research Board, Washington, D.C., 1-7.

Christensen, D. W., Pellinen, T. K., and Bonaquist, R. F. (2003). "Hirsch model for estimating the modulus of asphalt concrete." Asph. Paving Technol., 72, 97-121.

Federal Highway Administration (FHWA). (2000). "Temperature Predictions and Adjustment Factors for Asphalt Pavement." Publication No. FHWA-RD-98-085, FHWA, Research and Development, McLean, Va.

Fwa, T. F., Tan, C. Y., and Chan, W. T. (1997). "Back-calculation analysis of pavement-layer moduli using genetic algorithms." Transportation Research Record. 1570, Transportation Research Board, Washington, D.C., $134-142$.

Hirsch, T. J. (1962). "Modulus of elasticity of concrete affected by elastic moduli of cement paste matrix aggregate." J. Am. Concr. Inst., 59, 427-451.

Inge, E. H., and Kim, Y. R. (1995). "Prediction of effective asphalt layer temperature." Transportation Research Record. 1473, Transportation Research Board, Washington, D.C., 93-100.

Kim, Y. R., and Lee, Y.-C. (1995). "Interrelationships among stiffnesses of asphalt-aggregate mixtures." Asph. Paving Technol., 64, 575-609.

Mirza, M. W., and Witczak, M. W. (1995). "Development of a global aging System for short and long term aging of asphalt cements." Asph. Paving Technol., 64, 393-430.

National Cooperative Highway Research Program (NCHRP). (2002). 
"Simple performance test for superpave mix design." NCHRP Rep. No. 465, Transportation Research Board, Washington, D.C.

National Cooperative Highway Research Program (NCHRP). (2004). "Development of the 2002 guide for the design of new and rehabilitated pavement structures: Phase II." NCHRP 1-37A, Transportation Research Board, Washington, D.C.

Park, D. Y., Buch, N., and Chatti, K. (2001). "Effective layer temperature prediction model and temperature correction via falling weight deflectometer deflections." Transportation Research Record. 1764, Transportation Research Board, Washington, D.C., 97-111.

Park, H. M., Kim, Y. R., and Park, S. (2002). "Temperature correction of multiload-level falling weight deflectometer deflections." Transportation Research Record. 1806, Transportation Research Board, Washington, D.C., 3-8.

Park, S. W., and Kim, Y. R. (1997). "Temperature correction of backcalculated moduli and deflections using linear viscoelasticity and time-temperature superposition." Transportation Research Record. 1570, Transportation Research Board, Washington, D.C., 108-117.

Pellinen, T. K. (2001). "Investigation of the use of dynamic modulus as an indicator of HMA performance." Ph.D. dissertation, Arizona State Univ., Tempe, Ariz.

Romanoschi, S. A., Gisi, A. J., Portillo, M., and Dumitru, S. (2008). "The first findings from the Kansas perpetual pavements experiment." Transportation Research Record. 2068, Transportation Research Board, Washington, D.C., 41-48

Shao, L., Park, S. W., and Kim, Y. R. (1997). "Simplified procedure for prediction of asphalt pavement subsurface temperatures based on heat transfer theories." Transportation Research Record. 1568, Transportation Research Board, Washington, D.C., 114-123.

Witczak, M. W., Pellinen, T. K., and El-Basyouny, M. M. (2002). "Pursuit of the simple performance test for asphalt concrete fracture/ cracking." Asph. Paving Technol., 71, 767-778. 